\title{
"Nuclear Reprogramming" and "Epigenetic Reprogramming"
}

\author{
Takashi Tada $^{1 *}$, Hironobu Kimura ${ }^{1}$ and Masako Tada ${ }^{1,2}$ \\ ${ }^{1}$ Institute for Frontier Medical Sciences, Kyoto University, 53 Kawahara-cho, Shogoin, Sakyo-ku, \\ Kyoto 606-8507, Japan \\ ${ }^{2}$ ReproCELL inc., 1-1-1 Uchisaiwai-cho, Chiyoda-ku, Tokyo 100-0011, Japan
}

\section{Introduction}

"Nuclear reprogramming" is a phenomenon regulated by complex mechanisms that lead to the restoration of pluripotential competence in specialized somatic nuclei. Nuclear reprogramming is induced by changes in epigenetic modifications, known collectively as "epigenetic reprogramming". In somatic cell development, on-off switching of certain key genes, which function in determining cell fate in a particular direction, is regulated through epigenetic reprogramming in restricted regions of the genome. In nuclear reprogramming, genome-wide epigenetic reprogramming, which triggers a global restoration of epigenetic memory in the genome leading to transformation from a specified to a default nuclear state, is crucial. Genome-wide epigenetic reprogramming occurs in nuclear reprogramming with the nuclear transfer of somatic cells to enucleated oocytes and via cell hybridization between embryonic stem cells and adult somatic cells, and also in germ cell and early embryonic development but not in somatic cell development. Global chromatin de-condensation marked by histone $\mathrm{H} 3$ lysine 4 methylation is mechanistically linked with the genome-wide epigenetic reprogramming. At least two steps; 1) erasure of the somatic epigenotype induced by the genome-wide epigenetic reprogramming and 2) establishment of a pluripotential cell-specific epigenotype by local epigenetic reprogramming through the activity of key players including Oct4, Sox2, Ehz2 and Nanog, may be required for conferring and maintaining pluripotential competence in the reprogrammed somatic nuclei.

Received: August 16, 2004

Accepted: August 24, 2004

*To whom correspondence should be addressed.

e-mail: ttada@frontier.kyoto-u.ac.jp

\section{Nuclear Reprogramming in Early Embryonic Development}

Our body is built of an incredible variety of cell and tissue types, which develop from a single fertilized egg through embryogenesis. Cells are basically classified into two types: somatic cells and germ cells. Somatic cells function in forming and maintaining body parts only for one generation, whereas germ cells including gametes and their precursor cells are diversified for transmitting genetic information to the next generation. Remarkably, in germ cell and early embryonic development but not in somatic cell development, two waves of genome-wide epigenetic reprogramming take place in primordial germ cells (PGCs) when entering the gonads and in the preimplantation embryos, respectively [1]. The PGC-specific genome-wide epigenetic reprogramming plays an important role in resetting parental epigenetic memories (including imprints), whereas the early embryo-specific genomewide epigenetic reprogramming functions to erase the gamete-specific epigenetic memories (excluding imprints) required for equalizing the function of the paternal and maternal genome as detected by global DNA de-methylation and histone acetylation $[2,3]$.

A germ cell determinant, germ plasm (polar plasm) is accumulated as a maternal factor in the eggs of Drosophila melanogaster, Caenorhabdities elegans and Xenopus laevis, but it is believed that germ plasm does not exist in mammalian eggs [4], suggesting that germ cell and somatic cell lineages are not determined in the early embryos. In the mouse, PGCs are first identified as alkaline phosphate-positive cells clustering in the proximal region of allantois of the E7.25 embryo [5]. The emergence of these PGCs is induced by the synergistic action of extrinsic signals, BMP4 and BMP8B, secreted from the extraembryonic ectoderm 


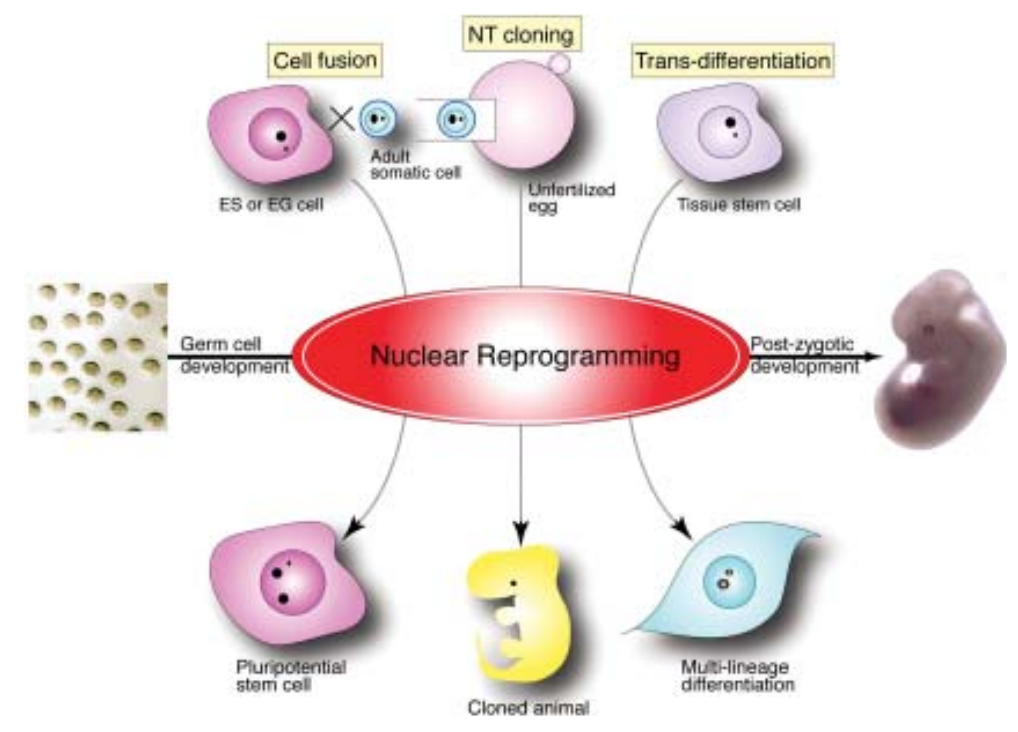

Fig. 1. Nuclear reprogramming in vivo and in vitro. NT: nuclear transplantation. ES: embryonic stem. EG: embryonic germ.

adjacent to the epiblast of E5.5 embryos $[6,7]$. Furthermore, Smad5 is involved in PGC generation and localization as a signal mediator downstream of the BMP pathway [8]. The hypothesis is proposed that germ line-competent cells are marked by an interferoninducible transmembrane protein, Ifitm3 (Fragilis, mil-1), in the E6.0-E7.5 embryos $[9,10]$ and then PGCs are specified by reduction in Ifitm 3 and subsequent increase in Stella/PGC7 $[9,11]$ and Thap (Tissue nonspecific alkaline phosphatase) [12] in the E7.25-7.5 embryos. In the PGCs specified by the marker genes, the parentally inherited epigenotype is retained. Based on the kinetics of DNA methylation of imprinted and non-imprinted genes, the genome-wide epigenetic reprogramming is initiated in the migrating PGCs of E9.5 embryos and subsequently completed soon after their entry into the genital ridges in both E12.5 male and female embryos to build an equivalent epigenetic state prior to the diversification to male and female gametes [13-20]. Reactivation of the inactivated $X$ chromosome in female PGCs also occurs in the gonads of E11.5-12.5 embryos [21, 22]. After fertilization, sperm-derived chromatin is drastically transformed by the activity of the nucleoplasmin due to the exchange of sperm-specific basic proteins (protamines) to maternal acetylated histones [23], resulting in the onset of the equalization of paternal and maternal genomes. Post-zygotic genome-wide DNA de-methylation takes place in early cleavage stages and DNA re-methylation is linked to the first-lineage cell differentiation during mammalian development [2]. Thus, genome-wide reprogramming is intrinsically linked to nuclear reprogramming in the germ cell and preimplantation development (Fig. 1), but the molecular mechanisms of nuclear reprogramming are largely unknown.

\section{Nuclear Reprogramming via Nuclear Transplantation of Somatic Cells}

The nuclear reprogramming activity of oocytes was first demonstrated with the successful production of cloned frogs by nuclear transplantation of the intestinal endoderm cells of feeding tadpoles into activated enucleated eggs [24]. More recently, nuclear transplantation of specialized somatic cells into enucleated oocytes demonstrated that mammalian oocytes also retain a nuclear reprogramming capacity as shown by the production of cloned animals such as sheep, cows, mice, pigs, cats, rats and monkeys [25, 26] (Fig. 1). Thus, amphibian and mammalian oocytes share an intrinsic nuclear reprogramming activity, and at least in part, reprogramming molecules and mechanisms, but the primary loss of eggs receiving transplanted nuclei of somatic cells differs in Amphibia and mammals. In mammals, the developmental loss occurs during relatively late stages, whereas in Amphibia, cloned eggs stop dividing in the early cleavage stages, suggesting that these temporal 
variations in embryonic loss probably reflect different difficulties encountered after the nuclear transplantation of somatic nuclei in Amphibia and mammals [27]. In mammals, it has been suggested that the developmental loss of cloned embryos could be caused by insufficient nuclear reprogramming of somatic nuclei. This is supported by the observed expression of somatic nucleus-derived Oct4-GFP in a limited number of cloned blastocysts [28], aberrant reactivation of Oct4related genes [29], and abnormal hyper-methylation of histone H3 lysine 9 (K9) associated with DNA hypermethylation in cloned preimplantation embryos [30, 31]. Another interesting suggestion is that developmental failure is due to a technical factor associated with enucleation with the maternal spindle proteins required for maintaining ploidy through the initial cleavages [32]. But it is largely unclear what the mechanisms and key molecules responsible for insufficient nuclear reprogramming and full nuclear reprogramming are.

Nuclear reprogramming of adult somatic cells or tissue stem cells is of interest as a procedure for generating personalized pluripotential stem cells, which is the ultimate cell source (stem cells of the second generation) of therapeutic materials for use in regenerative medicine. The personalized stem cells are pluripotential, self-renewing and immunologically syngeneic to the original somatic cell (the somatic cell donor). Therefore, the immune system of the somatic cell donor will be completely tolerant of derivatives from personalized stem cells. In fact, mouse embryonic stem (ES) cells derived from cloned blastocysts created by nuclear transplantation of somatic cell nuclei have been produced [33-35]. Furthermore, as a therapeutic model system in the mouse, the phenotype of immunodeficient Rag2(-/-) is rescued by grafting hematopoietic precursors generated from cloned ES cells with gene therapy with the wild-type Rag2 gene [36]. Recent developments in the field of stem cell research include the successful generation of mouse sperm and oocytes from ES cells in culture [37-39]. A combination of these newly established technologies may facilitate cell replacement with less ethical issues.

\section{Nuclear Reprogramming via Cell Fusion with Embryonic Stem Cells}

Mouse ES cells derived from the inner cell mass cells of blastocysts are defined by almost indefinite proliferation under appropriate culture conditions, without a loss of differentiation potential, into the cell types of adult somatic and germ cells [40,41]. The successful establishment of human ES cells from blastocysts has also been reported [35, 42, 43]. An important finding is that ES cells have an intrinsic capacity for the epigenetic reprogramming of somatic genomes after cell fusion [44-46] (Fig. 2). In hybrid cells between ES cells and adult thymocytes, nuclear reprogramming of somatic genomes has been shown by 1 ) the contribution of ES hybrid cells into normal embryogenesis of chimeras, 2 ) the reactivation of the silenced $X$ chromosome derived from a female somatic cell, 3) the reactivation of pluripotential cell-specific genes, Oct4, Xist and Tsix, which are derived from a somatic cell, 4 ) the re-differentiation down variety of cell types in teratomas, 5) the tissue-specific gene expression from reprogrammed somatic genomes in addition to $E S$ genomes in vivo in differentiated teratomas and in vitro in differentiated neuronal cells and 6 ) the acquisition of pluripotential cell-specific histone-tail modifications in reprogrammed somatic genomes. More interestingly, cell fusion experiments on somatic cells and embryonic germ (EG) cells, particularly those derived from gonadal primordial germ cells of mouse 11.5-12.5 dpc embryos demonstrate that EG cells possess additional potential for inducing reprogramming of somatic cell-derived parental imprints accompanied by a disruption of the parental-originspecific DNA methylation of imprinted genes [16, 47]. Therefore, cell fusion with pluripotential stem cells is now recognized as an effective approach to elucidating the mechanism of nuclear reprogramming concerned with DNA and chromatin modifications.

More recent evidence shows that neurosphere and bone marrow cells will undergo nuclear reprogramming after spontaneous cell fusion, when co-cultured with ES cells in vitro [48, 49]. In vivo, the contribution of spontaneous cell fusion to the regeneration of tissues has been proven by the transdifferentiation of bonemarrow-derived cells as hybrid cells into Purkinje neurons, cardiomyocytes and hepatocytes [50-53]. Thus, the nuclear reprogramming of somatic cells by in vivo cell fusion plays an important role in maintaining the homeostasis of some tissues through regeneration during defined self-renewal and after tissue damage, although not in all cases of spontaneous tissue repair $[54,55]$.

\section{Molecular Mechanism of Nuclear Reprogramming}

Nuclear reprogramming is regulated by complex mechanisms that lead to the restoration of pluripotential 


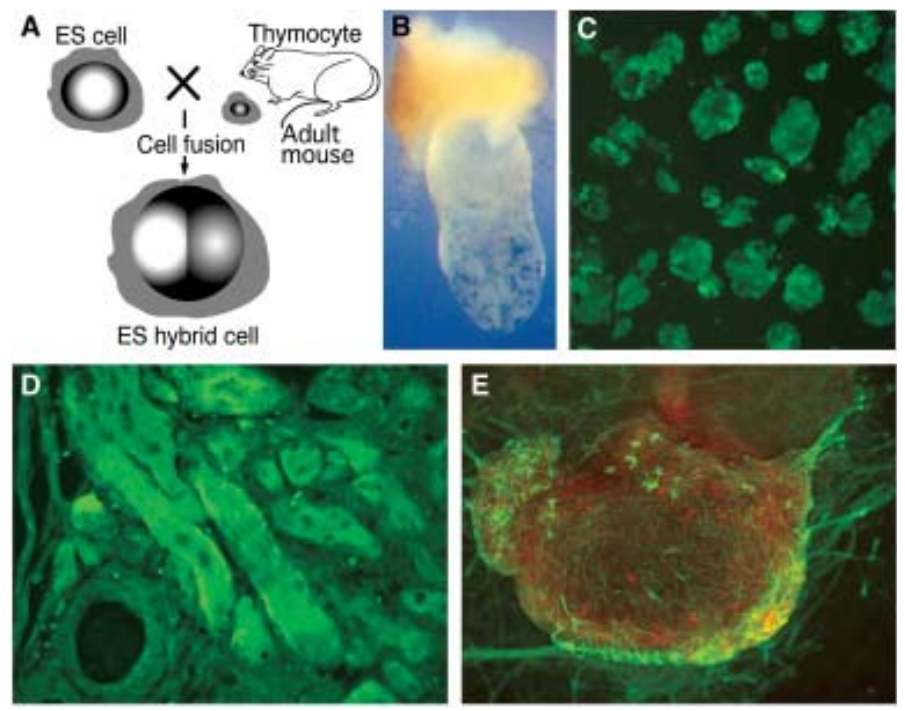

Fig. 2. Nuclear reprogramming of somatic nuclei by cell fusion with embryonic stem (ES) cells. (A) Cell fusion between ES cells and thymocytes derived from adult mice. (B) A representative E7.5 chimeric embryo with ES hybrid cells. ES hybrid cell derivatives are visualized as blue cells by X-gal staining. (C) Reactivation of the Oct4-GFP reporter gene in ES hybrid cells. The Oct4-GFP reduced in somatic cells is increased and stably expressed after cell fusion with ES cells. (D) In vivo differentiation of ES hybrid cells in teratoma. ES hybrid cells differentiate to muscle cells positive for immunoreaction with anti-Desmine antibody. (E) In vitro differentiation of ES hybrid cells. Neurofilament-positive (green) and tyrosine hydroxylasepositive (red) cells are efficiently generated from ES hybrid cells by co-culture with PA6 stromal cells.

competence in specialized somatic nuclei. Spontaneous transformation from somatic cells to pluripotential stem cells has not been found in vertebrates, suggesting that the process of nuclear reprogramming may be firmly prohibited and consist of complicated multi-step events. In Amphibia, somatic nuclei injected into an oocyte underwent a large increase in volume and dispersion of their chromatin [27]. Furthermore, new protein synthesis from the injected mouse and human nuclei is induced in Xenopus oocytes [56]. In mouse germ cell development, an enlargement of the nucleus in volume is classically observed in PGCs soon after entry into genital ridges at the stage when the PGC-specific genome-wide epigenetic reprogramming takes place. These findings indicate that the chromatin of somatic nuclei may be de-condensed after nuclear reprogramming.

During nuclear reprogramming, it is expected that DNA and chromatin modifications should be significantly effected. As epigenetic modifications, replication timing, DNA cytosine methylation, histone acetylation, histone methylation, histone variant, phosphorylation, ubiquitination, sumoylation, glycosylation and ADP ribosylation are believed to be involved in regulating the transcriptional activation or repression of genes. The histone modifications are thought to play certain key roles in regulating gene activity, most likely through the modification of the chromatin structure [57]. Regarding histone acetylation and methylation, to date at least eight acetylatable lysine positions are known in the $\mathrm{N}$-termini of histones $\mathrm{H} 3$ (K9, K14, K18, K23) and $\mathrm{H} 4$ (K5, K8, K12, K16) and six methylatable lysine positions exist in those of histones $\mathrm{H} 3$ ( $\mathrm{K} 4, \mathrm{~K} 9, \mathrm{~K} 27, \mathrm{~K} 36, \mathrm{~K} 79)$ and $\mathrm{H} 4$ (K20). In general, the acetylation of histones $\mathrm{H} 3$ and $\mathrm{H} 4$ correlates with gene activation, while deacetylation correlates with gene silencing [58]. The methylation of H3-K4 also marks active chromatin, which contrasts with the modification of inactive chromatin by the 


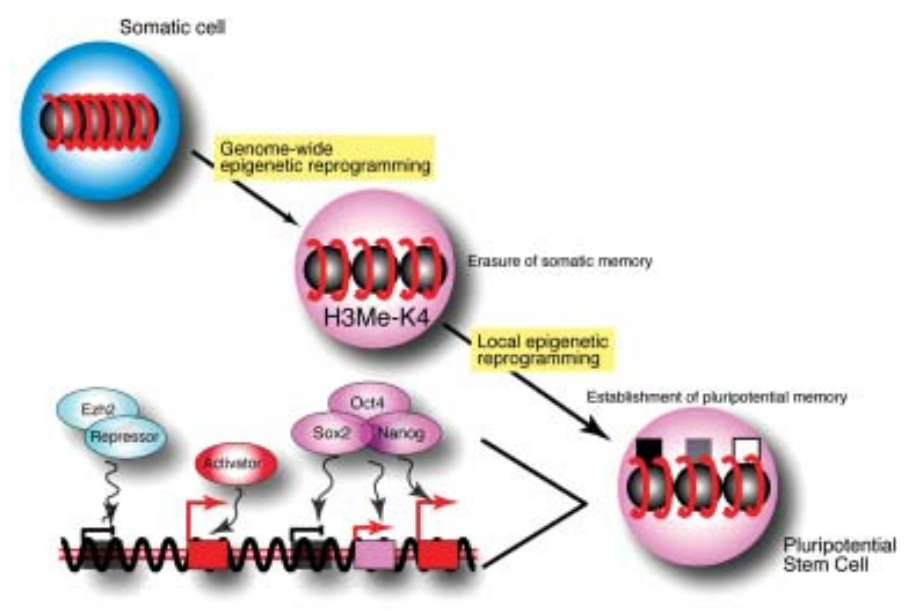

Fig. 3. Nuclear reprogramming of somatic nuclei through two distinguishable events. The first event is the erasure of somatic memory due to genome-wide epigenetic reprogramming. The second event is the establishment of pluripotential cell-specific memory built by local epigenetic reprogramming. H3Me-K4; histone $\mathrm{H} 3$ methylation at lysine 4 .

methylation of H3-K9 [59]. The methylation of H3-K27 is an epigenetic marker for the recruitment of the polycomb group (Pc-G) complexes [60] and is prominent in the inactivated $X$ chromosome of female mammalian somatic cells $[61,62]$. The amino-terminal tail of histone $\mathrm{H} 3$ is subject to three distinctive methylation states, mono-, di- and tri-methylation. Pericentric heterochromatin is enriched in tri-methylated $\mathrm{H} 3-\mathrm{K} 9$, whereas centromeric regions are enriched in dimethylated forms [59]. At H3-K27, both di- and trimethylation are observed across several nucleosomes, and it is the tri-methylated form that has been found to induce the stable recruitment of PC-G complexes [63]. At $\mathrm{H} 3-\mathrm{K} 4$, fully activated promoters are enriched with the tri-methylated form, whereas $\mathrm{H} 3-\mathrm{K} 4$ di-methylation correlates with the basal transcription-permissive state [64]. Therefore, it appears that di-methylation activity prepares histones for a tri-methylating activity, which then propagates stably activated or silenced chromatin domains.

In the somatic cell-derived nuclei fully reprogrammed in ES hybrid cells, post-translational histone acetylation and methylation of histone $\mathrm{N}$ termini are analyzed with a technique of chromatin immunoprecipitation. The reprogrammed somatic genome becomes globally hyper-acetylated at histones $\mathrm{H} 3$ and $\mathrm{H} 4$. Of note, histone $\mathrm{H} 3-\mathrm{K} 4$ become hyper-di and tri-methylated irrespective of the gene activity [65]. De-condensed chromatin marked by histone H3-K4 hyper-methylation is globally formed by genome-wide epigenetic reprogramming. This event may be linked with the swelling of the nucleus in PGCs when genome-wide epigenetic reprogramming takes place. Global epigenetic reprogramming may lead to the formation of basal transcription activation-permissive chromatin and function in erasing pre-established somatic cell-specific epigenetic memory prior to the building of the pluripotential cell-specific epigenotype. Subsequently, the pluripotential stem cell-specific epigenotype is established by the repression of somatic cell-specific genes and activation of pluripotential cell-specific genes through local epigenetic reprogramming by the activities of pluripotential cell-specific key regulators such as Oct4, Sox2, Ezh2 and Nanog [66-71]. Therefore, we propose that the nuclear reprogramming of somatic nuclei involves at least two distinct events, 1) erasure of somatic cell-specific epigenetic memory by genomewide epigenetic reprogramming and 2) establishment and maintenance of a pluripotential cell-specific epigenotype by local epigenetic reprogramming (Fig. 3). In the second event, it is likely that the key genes work cooperatively through molecular communication in the stem cell-specific regulatory network.

\section{Conclusion}

Genome-wide epigenetic reprogramming is a crucial molecular event needed to induce sufficient nuclear 
reprogramming in germ cell and early embryonic development in vivo, and also by nuclear transplantation of specialized somatic nuclei into unfertilized oocytes and cell fusion between ES or EG cells and adult somatic cells in vitro. Nuclear reprogramming technology is required for producing second generation stem cells, which are immunologically syngeneic pluripotential stem cells generated from personal somatic cells. Identification of the molecular mechanisms and factors implicated in the nuclear reprogramming will provide a clue to the mechanisms of succession of life from generation to generation. A greater understanding of these mechanisms will bring biomedical applications and basic science in the field of stem cell biology closer together.

\section{References}

1) Li, E. (2002): Chromatin modification and epigenetic reprogramming in mammalian development. Nat. Rev. Genet., 3, 662-673.

2) Reik, W., Dean, W. and Walter, J. (2001): Epigenetic reprogramming in mammalian development. Science, 293, 1089-1093.

3) Adenot, P.G., Mercier, Y., Renard, J.P. and Thompson, E.M. (1997): Differential H4 acetylation of paternal and maternal chromatin precedes DNA replication and differential transcriptional activity in pronuclei of 1-cell mouse embryos. Development, 124, 4615-4625.

4) Snow, M.H.L. and Monk, M. (1983): Emergence and migration of mouse primordial germ cells. In: In Current Problems in Germ Cell Differentiation (McLaren, A. and Wylie, C.C., eds.), pp. 115-135, Cambridge University Press, Cambridge.

5) Ginsburg, M., Snow, M.H. and McLaren, A. (1990): Primordial germ cells in the mouse embryo during gastrulation. Development, 110, 521-528.

6) Lawson, K.A., Dunn, N.R., Roelen, B.A., Zeinstra, L.M., Davis, A.M., Wright, C.V., Korving, J.P. and Hogan, B.L. (1999): Bmp4 is required for the generation of primordial germ cells in the mouse embryo. Genes Dev., 13, 424-436.

7) Ying, Y., Qi, X. and Zhao, G.Q. (2001): Induction of primordial germ cells from murine epiblasts by synergistic action of BMP4 and BMP8B signaling pathways. Proc. Natl. Acad. Sci. USA., 98, 7858-7862.

8) Chang, H. and Matzuk, M.M. (2001): Smad5 is required for mouse primordial germ cell development. Mech. Dev., 104, 61-67.

9) Saitou, M., Barton, S.C. and Surani, M.A. (2002): A molecular programme for the specification of germ cell fate in mice. Nature, 418, 293-300.

10) Tanaka, S.S., Nagamatsu, G., Tokitake, Y., Kasa, M., Tam, P.P. and Matsui, Y. (2004): Regulation of expression of mouse interferon-induced transmembrane protein like gene-3, Ifitm3 (mil-1, fragilis), in germ cells. Dev. Dyn., 230, 651-659.

11) Sato, M., Kimura, T., Kurokawa, K., Fujita, Y., Abe, K., Masuhara, M., Yasunaga, T., Ryo, A., Yamamoto, M. and Nakano, T. (2002): Identification of PGC7, a new gene expressed specifically in preimplantation embryos and germ cells. Mech. Dev., 113, 91-94.

12) MacGregor, G.R., Zambrowicz, B.P. and Soriano, P. (1995): Tissue non-specific alkaline phosphatase is expressed in both embryonic and extraembryonic lineages during mouse embryogenesis but is not required for migration of primordial germ cells. Development, 121, 1487-1496.

13) Brandeis, M., Kafri, T., Ariel, M., Chaillet, J.R., McCarrey, J., Razin, A. and Cedar, H. (1993): The ontogeny of allelespecific methylation associated with imprinted genes in the mouse. EMBO J., 12, 3669-3677.

14) Szabo, P.E. and Mann, J.R. (1995): Biallelic expression of imprinted genes in the mouse germ line: implications for erasure, establishment, and mechanisms of genomic imprinting. Genes Dev., 9, 1857-1868.

15) Obata, Y., Kaneko-Ishino, T., Koide, T., Takai, Y., Ueda, T., Domeki, I., Shiroishi, T., Ishino, F. and Kono, T. (1998): Disruption of primary imprinting during oocyte growth leads to the modified expression of imprinted genes during embryogenesis. Development, 125, 1553-1560.

16) Tada, T., Tada, M., Hilton, K., Barton, S.C., Sado, T., Takagi, N. and Surani, M.A. (1998): Epigenotype switching of imprintable loci in embryonic germ cells. Dev. Gene Evol., 207, 551-561.

17) Hajkova, P., Erhardt, S., Lane, N., Haaf, T., El-Maarri, O., Reik, W., Walter, J. and Surani, M.A. (2002): Epigenetic reprogramming in mouse primordial germ cells. Mech. Dev., 117, 15-23.

18) Lee, J., Inoue, K., Ono, R., Ogonuki, N., Kohda, T., Kaneko-Ishino, T., Ogura, A. and Ishino, F. (2002): Erasing genomic imprinting memory in mouse clone embryos produced from day 11.5 primordial germ cells. Development, 129, 1807-1817.

19) Sato, S., Yoshimizu, T., Sato, E. and Matsui, Y. (2003): Erasure of methylation imprinting of Igf $2 \mathrm{r}$ during mouse primordial germ-cell development. Mol. Reprod. Dev., 65, 41-50.

20) Yamazaki, Y., Mann, M.R., Lee, S.S., Marh, J., McCarrey, J.R., Yanagimachi, R. and Bartolomei, M.S. (2003): Reprogramming of primordial germ cells begins before migration into the genital ridge, making these cells inadequate donors for reproductive cloning. Proc. Natl. Acad. Sci. USA., 100, 12207-12212.

21) Monk, M. and McLaren, A. (1981): X-chromosome activity in foetal germ cells. J. Embryol. Exp. Morph., 63, 75-84.

22) Tam, P.P., Zhou, S.X. and Tan, S.-S. (1994): Xchromosome activity of the mouse primordial germ cells revealed by the expression of an X-linked lacZ transgene. Development, 120, 2925-2932.

23) Philpott, A. and Leno, G.H. (1992): Nucleoplasmin 
remodels sperm chromatin in Xenopus egg extracts. Cell, 69, 759-767.

24) Gurdon, J. (1962): The developmental capacity of nuclei taken from intestinal epithelial cells of feeding tadpoles. J. Embryol. Exp. Morph., 10, 622-640.

25) Wilmut, I., Schnieke, A.E., McWhir, J., Kind, A.J. and Campbell, K.H.S. (1997): Viable offspring derived from fetal and adult mammalian cells. Nature, 385, 810-813.

26) Tada, T. and Tada, M. (2001): Toti-/pluripotential stem cells and epigenetic modifications. Cell Struct. Funct., 26, 149-160.

27) Gurdon, J.B., Byrne, J.A. and Simonsson, S. (2003): Nuclear reprogramming and stem cell creation. Proc. Natl. Acad. Sci. USA., 100 (Suppl 1), 11819-11822.

28) Boiani, M., Eckardt, S., Scholer, H.R. and McLaughlin, K.J. (2002): Oct4 distribution and level in mouse clones: consequences for pluripotency. Genes Dev., 16, 12091219.

29) Bortvin, A., Eggan, K., Skaletsky, H., Akutsu, H., Berry, D.L., Yanagimachi, R., Page, D.C. and Jaenisch, R. (2003): Incomplete reactivation of Oct4-related genes in mouse embryos cloned from somatic nuclei. Development, 130, 1673-1680.

30) Dean, W., Santos, F., Stojkovic, M., Zakhartchenko, V., Walter, J., Wolf, E. and Reik, W. (2001): Conservation of methylation reprogramming in mammalian development: aberrant reprogramming in cloned embryos. Proc. Natl. Acad. Sci. USA., 98, 13734-13738.

31) Santos, F., Zakhartchenko, V., Stojkovic, M., Peters, A., Jenuwein, T., Wolf, E., Reik, W. and Dean, W. (2003): Epigenetic marking correlates with developmental potential in cloned bovine preimplantation embryos. Curr. Biol., 13, 1116-1121.

32) Simerly, C., Dominko, T., Navara, C., Payne, C., Capuano, S., Gosman, G., Chong, K.Y., Takahashi, D., Chace, C., Compton, D., Hewitson, L. and Schatten, G. (2003): Molecular correlates of primate nuclear transfer failures. Science, 300, 297.

33) Munsie, M.J., Michalska, A.E., O’Brien, C.M., Trounson, A.O., Pera, M.F. and Mountford, P.S. (2000): Isolation of pluripotent embryonic stem cells from reprogrammed adult mouse somatic cell nuclei. Curr. Biol., 10, 989-992.

34) Kawase, E., Yamazaki, Y., Yagi, T., Yanagimachi, R. and Pedersen, R.A. (2000): Mouse embryonic stem (ES) cell lines established from neuronal cell-derived cloned blastocysts. Genesis, 28, 156-163.

35) Hwang, W.S., Ryu, Y.J., Park, J.H., Park, E.S., Lee, E.G., Koo, J.M., Jeon, H.Y., Lee, B.C., Kang, S.K., Kim, S.J., Ahn, C., Hwang, J.H., Park, K.Y., Cibelli, J.B. and Moon, S.Y. (2004): Evidence of a pluripotent human embryonic stem cell line derived from a cloned blastocyst. Science, 303, 1669-1674.

36) Rideout, W.M. 3rd, Hochedlinger, K., Kyba, M., Daley, G.Q. and Jaenisch, R. (2002): Correction of a genetic defect by nuclear transplantation and combined cell and gene therapy. Cell, 109, 17-27.

37) Toyooka, Y., Tsunekawa, N., Takahashi, Y., Matsui, Y.,
Satoh, M. and Noce, T. (2000): Expression and intracellular localization of mouse Vasa-homologue protein during germ cell development. Mech. Dev., 93, 139-149.

38) Hubner, K., Fuhrmann, G., Christenson, L.K., Kehler, J., Reinbold, R., De La Fuente, R., Wood, J., Strauss, J.F. 3rd, Boiani, M. and Scholer, H.R. (2003): Derivation of oocytes from mouse embryonic stem cells. Science, 300, 12511256.

39) Geijsen, N., Horoschak, M., Kim, K., Gribnau, J., Eggan, K. and Daley, G.Q. (2004): Derivation of embryonic germ cells and male gametes from embryonic stem cells. Nature, 427, 148-154.

40) Evans, M.J. and Kaufman, M.H. (1981): Establishment in culture of pluripotential cells from mouse embryos. Nature, 292, 154-156.

41) Martin, G.R. (1981): Isolation of a pluripotent cell line from early mouse embryos cultured in medium conditioned by teratocarcinoma stem cells. Proc. Natl. Acad. Sci. USA., 78, 7634-7638.

42) Thomson, J.A., Itskovitz-Eldor, J., Shapiro, S.S., Waknitz, M.A., Swiergiel, J.J., Marshall, V.S. and Jones, J.M. (1998): Embryonic stem cell lines derived from human blastocysts. Science, 282, 1145-1147.

43) Amit, M., Carpenter, M.K., Inokuma, M.S., Chiu, C.P., Harris, C.P., Waknitz, M.A., Itskovitz-Eldor, J. and Thomson, J.A. (2000): Clonally derived human embryonic stem cell lines maintain pluripotency and proliferative potential for prolonged periods of culture. Dev. Biol., 227, 271-278.

44) Tada, M., Takahama, Y., Abe, K., Nakatsuji, N. and Tada, T. (2001): Nuclear reprogramming of somatic cells by in vitro hybridization with ES cells. Curr. Biol., 11, 15531558.

45) Kimura, H., Tada, M., Hatano, S., Yamazaki, M., Nakatsuji, N. and Tada, T. (2002): Chromatin reprogramming of male somatic cell-derived XIST and TSIX in ES hybrid cells. Cytogenet. Genome Res., 99, 106-114.

46) Tada, M., Morizane, A., Kimura, H., Kawasaki, H., Ainscough, J.F., Sasai, Y., Nakatsuji, N. and Tada, T. (2003): Pluripotency of reprogrammed somatic genomes in embryonic stem hybrid cells. Dev. Dyn., 227, 504-510.

47) Tada, M., Tada, T., Lefebvre, L., Barton, S.C. and Surani, M.A. (1997): Embryonic germ cells induce epigenetic reprogramming of somatic nucleus in hybrid cells. EMBO J., 16, 6510-6520.

48) Terada, N., Hamazaki, T., Oka, M., Hoki, M., Mastalerz, D.M., Nakano, Y., Meyer, E.M., Morel, L., Petersen, B.E. and Scott, E.W. (2002): Bone marrow cells adopt the phenotype of other cells by spontaneous cell fusion. Nature, 416, 542-545.

49) Ying, Q.L., Nichols, J., Evans, E.P. and Smith, A.G. (2002): Changing potency by spontaneous fusion. Nature, 416, 545-548.

50) Vassilopoulos, G., Wang, P.R. and Russell, D.W. (2003): Transplanted bone marrow regenerates liver by cell fusion. Nature, 422, 901-904. 
51) Wang, X., Willenbring, H., Akkari, Y., Torimaru, Y., Foster, M., Al-Dhalimy, M., Lagasse, E., Finegold, M., Olson, S. and Grompe, M. (2003): Cell fusion is the principal source of bone-marrow-derived hepatocytes. Nature, 422, 897-901.

52) Alvarez-Dolado, M., Pardal, R., Garcia-Verdugo, J.M., Fike, J.R., Lee, H.O., Pfeffer, K., Lois, C., Morrison, S.J. and Alvarez-Buylla, A. (2003): Fusion of bone-marrowderived cells with Purkinje neurons, cardiomyocytes and hepatocytes. Nature, 425, 968-973.

53) Weimann, J.M., Johansson, C.B., Trejo, A. and Blau, H.M. (2003): Stable reprogrammed heterokaryons form spontaneously in Purkinje neurons after bone marrow transplant. Nat. Cell Biol., 5, 959-966.

54) Harris, R.G., Herzog, E.L., Bruscia, E.M., Grove, J.E., Van Arnam, J.S. and Krause, D.S. (2004): Lack of a fusion requirement for development of bone marrow-derived epithelia. Science, 305, 90-93.

55) Wurmser, A.E., Nakashima, K., Summers, R.G., Toni, N., D'Amour, K.A., Lie, D.C. and Gage, F.H. (2004): Cell fusion-independent differentiation of neural stem cells to the endothelial lineage. Nature, 430, 350-356.

56) Byrne, J.A., Simonsson, S., Western, P.S. and Gurdon, J.B. (2003): Nuclei of adult mammalian somatic cells are directly reprogrammed to oct- 4 stem cell gene expression by amphibian oocytes. Curr. Biol., 13, 1206-1213.

57) Lachner, M. and Jenuwein, T. (2002): The many faces of histone lysine methylation. Curr. Opin. Cell Biol., 14, 286298.

58) Fry, C.J. and Peterson, C.L. (2001): Chromatin remodeling enzymes: who's on first? Curr. Biol., 11, 185-197.

59) Lachner, M., O'Sullivan, R.J. and Jenuwein, T. (2003): An epigenetic road map for histone lysine methylation. J. Cell Sci., 116, 2117-2124.

60) Czermin, B., Melfi, R., McCabe, D., Seitz, V., Imhof, A. and Pirrotta, V. (2002): Drosophila enhancer of Zeste/ESC complexes have a histone $\mathrm{H} 3$ methyltransferase activity that marks chromosomal Polycomb sites. Cell, 111, 185196.

61) Plath, K., Fang, J., Mlynarczyk-Evans, S.K., Cao, R., Worringer, K.A., Wang, H., de la Cruz, C.C., Otte, A.P., Panning, B. and Zhang, Y. (2003): Role of histone H3 lysine 27 methylation in $\mathrm{X}$ inactivation. Science, 300, 131135.

62) Silva, J., Mak, W., Zvetkova, I., Appanah, R., Nesterova,
T.B., Webster, Z., Peters, A.H., Jenuwein, T., Otte, A.P. and Brockdorff, N. (2003): Establishment of histone h3 methylation on the inactive $\mathrm{X}$ chromosome requires transient recruitment of Eed-Enx1 polycomb group complexes. Dev. Cell, 4, 481-495.

63) Cao, R., Wang, L., Wang, H., Xia, L., Erdjument-Bromage, H., Tempst, P., Jones, R.S. and Zhang, Y. (2002): Role of histone H3 lysine 27 methylation in Polycomb-group silencing. Science, 298, 1039-1043.

64) Santos-Rosa, H., Schneider, R., Bernstein, B.E., Karabetsou, N., Morillon, A., Weise, C., Schreiber, S.L., Mellor, J. and Kouzarides, T. (2003): Methylation of histone h3 k4 mediates association of the isw1p ATPase with chromatin. Mol. Cell, 12, 1325-1332.

65) Kimura, H., Tada, M., Nakatsuji, N. and Tada, T. (2004): Histone code modifications on pluripotential nuclei of reprogrammed somatic cells. Mol. Cell. Biol., 24, 57105720.

66) Nichols, J., Zevnik, B., Anastassiadis, K., Niwa, H., Klewe-Nebenius, D., Chambers, I., Scholer, H. and Smith, A. (1998): Formation of pluripotent stem cells in the mammalian embryo depends on the POU transcription factor Oct4. Cell, 95, 379-391.

67) Niwa, H., Miyazaki, J. and Smith, A.G. (2000): Quantitative expression of Oct-3/4 defines differentiation, dedifferentiation or self-renewal of ES cells. Nat. Genet., 24, 372-376.

68) O'Carroll, D., Erhardt, S., Pagani, M., Barton, S.C., Surani, M.A. and Jenuwein, T. (2001): The polycomb-group gene Ezh2 is required for early mouse development. Mol. Cell. Biol., 21, 4330-4336.

69) Avilion, A.A., Nicolis, S.K., Pevny, L.H., Perez, L., Vivian, N. and Lovell-Badge, R. (2003): Multipotent cell lineages in early mouse development depend on SOX2 function. Genes Dev., 17, 126-140.

70) Mitsui, K., Tokuzawa, Y., Itoh, H., Segawa, K., Murakami, M., Takahashi, K., Maruyama, M., Maeda, M. and Yamanaka, S. (2003): The Homeoprotein Nanog Is Required for Maintenance of Pluripotency in Mouse Epiblast and ES Cells. Cell, 113, 631-642.

71) Chambers, I., Colby, D., Robertson, M., Nichols, J., Lee, S., Tweedie, S. and Smith, A. (2003): Functional expression cloning of nanog, a pluripotency sustaining factor in embryonic stem cells. Cell, 113, 643-655. 